Review Article

\title{
Mapping Global Research on Green Finance from 1989 to 2020: A Bibliometric Study
}

\author{
Xiaobing Yu, ${ }^{1}$ Ye Mao $\left(D,{ }^{2}\right.$ Dongmei Huang, ${ }^{2}$ Zhoubao Sun, ${ }^{2}$ and Tingliao $\mathrm{Li}^{3}$ \\ ${ }^{1}$ School of Information Engineering, Nanjing Audit University, Nanjing 211815, China \\ ${ }^{2}$ School of Engineering Audit, Jiangsu Key Laboratory of Public Project Audit, Nanjing Audit University, Nanjing 211815, China \\ ${ }^{3}$ School of Business, Nanjing Audit University, Nanjing 211815, China
}

Correspondence should be addressed to Ye Mao; maoye@nau.edu.cn

Received 16 March 2021; Revised 1 June 2021; Accepted 30 July 2021; Published 10 August 2021

Academic Editor: Jingfeng Yuan

Copyright (C) 2021 Xiaobing Yu et al. This is an open access article distributed under the Creative Commons Attribution License, which permits unrestricted use, distribution, and reproduction in any medium, provided the original work is properly cited.

Green finance is considered to be the financial support for green growth. It acts on the environmental protection industry through financial activities to reduce greenhouse gas emissions. It is a new financial model that combines financial and environmental protection activities. In order to explore the origin and development of this new financial model, namely, green finance, this study adopts the method of bibliometrics. Based on the database based on the Science Citation Index Expanded and Social Sciences Citation Index databases, the historical evolution of green finance and the classification of research hotspots are explored. The results show that green finance research has gone through three stages: the budding stage, the stable development stage, and the booming development stage. The research topics have also changed from the establishment of the green financial system to the difficulties faced by the green financial systems of various countries to the empirical evidence of the vigorous development of green finance. In addition, we have also established a three-dimensional framework (i.e., purpose, process, and participants, or 3P) of research hotspots in green finance to show a road map for future research directions.

\section{Introduction}

Due to the general neglect of the control of pollutant emissions, environmental pollution is becoming serious, and the global temperature is rising, and the ecological environment in which we live is greatly challenged [1-4]. To limit global warming to $1.5^{\circ} \mathrm{C}$ and prevent catastrophic climate change, governments have begun to adopt various economic measures to encourage adaptation and mitigation actions to sustainability [5]. The low-carbon economy concept with "low energy consumption and low pollution" as the core has quickly become the global consensus and the general principle guiding the economic development of various countries [6]. The low-carbon economy and the threat of climate change echo each other, providing a new direction for the innovation of traditional financial theory; that is, traditional financial theory and practice need to adapt to the development of the low-carbon economy [7]. As a result, green finance came into being. It is considered as a public policy mechanism to combine the world of finance and business with environmentally friendly behavior $[8,9]$. According to the Paris Climate Agreement (PCA) within the United Nations Framework Convention on Climate Change (UNFCCC) and the 2030 Agenda for Sustainable Development and its 2015 Sustainable Development Goals (SDGs), there is an immediate requirement of US\$ 1.5 trillion in green financing annually through 2030 to meet the targets $[10,11]$. Therefore, the green finance, mobilizing capital to enter the green market, has an indisputable role in responding to climate breakdown and the sustainability $[12,13]$.

Green finance refers to "the financing of investments that provide environmental benefits" [14]. It is an arena for diverse stakeholders, including producers, consumers, investors, and governments at individual, organizational, industrial, national, or transnational levels [15]. On one hand, green finance sets off proactive, eco-friendly behaviors, such as promoting mass transit, developing renewable energy, or 
the recycling of used goods $[16,17]$. On the other hand, green finance is about avoiding the extension of any business or activity that could be deleterious to the natural environment [18]. Given the paramount policy importance, green finance has frequently appeared in reports of national governments and international organizations since its emergence [19]. Intensive discussions have also interest from academics [20]. Significant scientific evidence indicates that green finance is widely embedded in renewable energy, energy efficiency [21], eco-innovation in technologies and processes [22], clean production [18], green transportation [23], green buildings [24], pollution prevention and control [4], land use [25], water and waste water management [26], sustainable living natural resources management [27], terrestrial and aquatic biodiversity conservation [13], and climate change adaptation [28]. However, despite these advances, existing studies are still scattered and fragmented in their own approaches and horizons [11]. This suggests that there is an urgent call to clearly sketch the contours of current status, form a proper understanding of the evolution trends, and shed light on future research directions towards green finance in the broadest sense.

As quantitative approach, the bibliometric analysis is regarded as an effective method for offering an in-depth and comprehensive understanding of emerging research areas $[29,30]$. Through a systematic investigation of existing studies, it could help scholars quickly identify the current research trend, hotspots, and future developments in a specific field by revealing the characteristics including topics, authors, publications, category, keywords, reference, citations, and intellectual structure [31].

Aiming to draw a big and fine-grained picture of relevant academic research, the current study adopts a bibliometric evaluation of research to make a contribution to the realm of green finance. First, it demonstrates the latest research status and evolution trends based on the quantity of literature, geographical distribution, journal distribution, productive authors, and institutions and cocitation analysis. Second, we longitudinally analyzed the evolution of the theme of green finance. Finally, a conceptual 3P framework (purpose, process, and participants) based on keyword clustering results is provided as a road map for future green finance research.

The rest of this paper is structured as follows: Section 2 presents data sources and research method, Section 3 describes the research network, Section 4 analyzes the evolutionary stage of the theme, and Section 5 outlines main conclusions and offers the recommendations, on the basis of the bibliometric investigation, for future work.

\section{Data Sources and Method}

2.1. Data Sources. Web of Science (WoS) is an authoritative literature database, which can also derive citation information for cocitation analysis. Therefore, scholars often use the Web of Science database when collecting literature data. The Science Citation Index Expanded (SCI-EXPANDED) and Social Sciences Citation Index
(SSCI) in the database were selected as our search source, topic $=$ "green finance," document type $=$ "article and review," the time span and language type are not limited, and finally 888 documents were obtained. The operation time is May 9, 2021.

\subsection{Research Method}

2.2.1. Social Network Analysis. Social network analysis is based on mathematical graph theory and is mainly used for network structure research. It can be used to analyze the authors, institutions, countries, journals, and other information of the literature. Using social network analysis methods to interpret the map can be further analyzed from the structure and indicators, so as to discover the important research content and knowledge structure in the map.

2.2.2. Cocitation Analysis. H. Small in 1973 proposed that the analysis of cocitation information can provide clues for the evolution of the discipline. Document cocitation means that two documents are cited by another document at the same time. Cocitation is considered to be one of the indicators for measuring the frontiers of disciplines. In other words, cocitation documents have common disciplinary basic knowledge and have guiding significance for subsequent innovative research.

2.2.3. Burst Detection. Burst detection is proposed by Kleinberg in 2002, which is to explore the research hotspots of the field by focusing on the change of the word frequency growth rate of a single word. It is generally believed that words with greater growth momentum indicate that they are more favored by researchers and paid more attention to by researchers. These newly emerging words may be more able to reveal research hotspots and frontier issues in a certain research field.

2.2.4. Keyword Cluster Analysis. Keyword cluster analysis is mainly used to mine research hotspots. In the literature, the author will highly generalize the research content of the article and then extract key keywords. Keywords are imported into the software and scientific algorithms divide these keywords into several groups and make the objects in the group similar, but the objects in different groups are different. Keyword cluster analysis is an advanced statistical method based on coword analysis.

\section{Research Results}

3.1. General Statistic. The change of the quantity of literature output is one of the important indicators to measure the research progress in this discipline. Referring to the annual change of the quantity of literature output in this discipline, we can grasp the historical track of its rise and fall. Figure 1 shows the time distribution of green finance research literature output. It can be seen from the figure that the research on green 


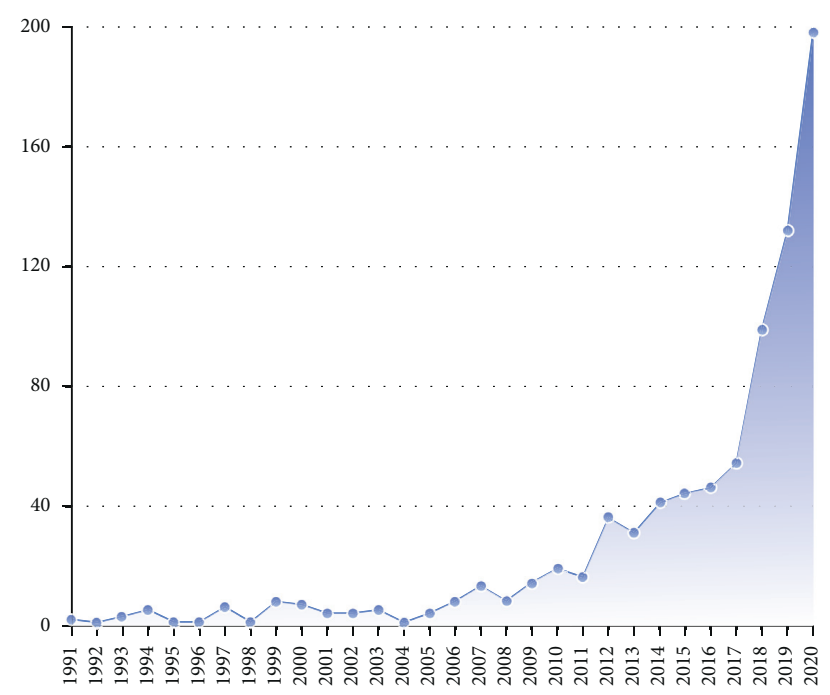

Figure 1: The distribution of global green finance publications.

finance began in 1991 and entered the discipline development period in 2012 after a slow growth of more than 20 years. The reason for the increase in the number of this paper may be that the global serious subprime crisis ended, the global economic recovery was established, and scholars began to consider how to use the sustainable development of financial instruments to develop the economy. The next turning point was in 2018 when the detailed negotiation of the Paris Agreement was completed during the discussion of the United Nations Framework Convention on Climate Change, and green finance entered a period of explosive growth.

3.2. Country Distribution. A total of 76 countries (regions) have participated in the field of green finance. Figure 2 lists the number of publications in the top 15 countries/regions and the $H$ index (the $H$ index is defined as follows: " $H$ of the NP papers published by a scholar is cited at least $H$ times, while the other NP-H papers are cited less than $H$ times"). The top 15 are 2 North American countries, 8 European countries, 3 Asian countries, 1 African country, and Australia. These countries are more concerned about energy and environmental issues than others. Their financial institutions have developed or participated in a corporate loan standard, the Equator Principles, which require financial institutions to evaluate environmental and social impacts as much as possible when investing in projects and to use financial leverage to promote the active role of the invested projects in protecting environmental sustainability [32]. The United States not only ranks first in the number of papers but also has the highest $H$ index. This shows that the United States also has a high level of papers, in both quantity and quality. Figure 3 shows a map of national productivity contributions. The top three countries with the largest nodes are the United States, China, and England. Figure 4 further shows the geographical distribution of the total number of publications. China, South Africa, and India are the only developing countries among the top 15 countries, but they account for $21.97 \%$ of publications. These three countries are huge

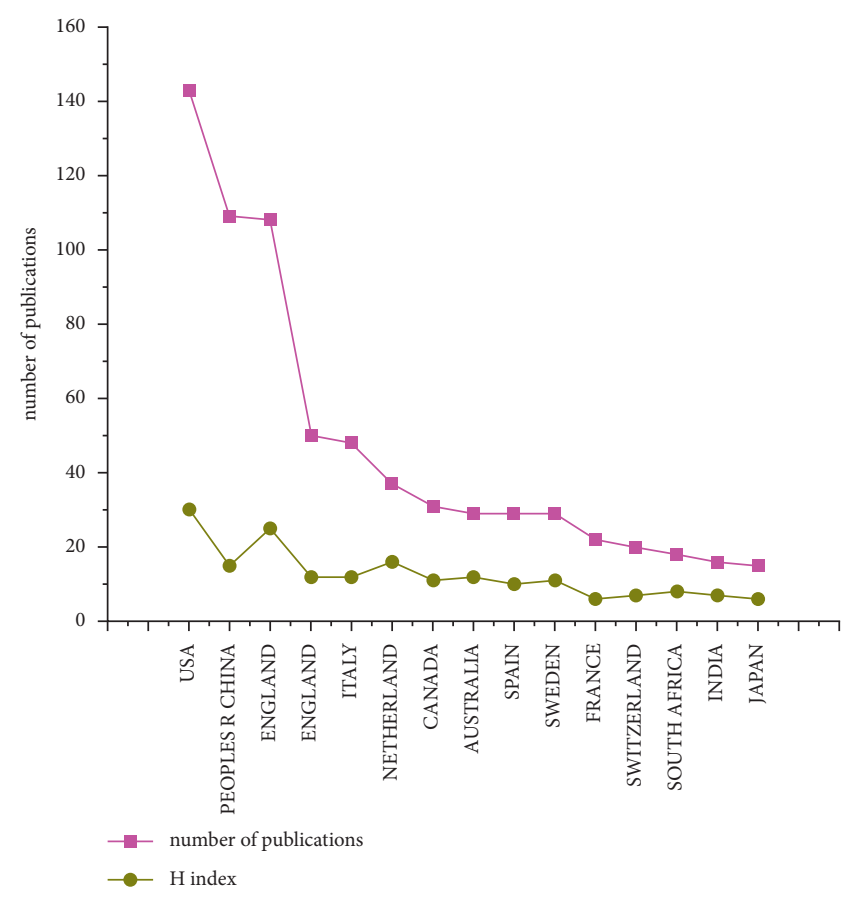

FIgURE 2: The top 15 productive countries.

energy-consuming developing economies and are under great pressure from resource shortages and environmental pollution, which is forcing them to use green financial means to protect the environment.

3.3. Authors and Institution Distribution. Green finance is an attractive topic with rich practical picture and theoretical production space. The core group refers to a group of authors who publish more papers and have greater influence. According to Price's theory [33], only a specific number of authors/institutions with publications in a certain field can become core authors/institutions. According to theoretical calculations, the scholars who have published 2 or more papers are the core authors of green finance, and institutions with a volume equal to or greater than 5 are core institutions. Among them, Chinese scholars are the most published scholars, with 35 people, accounting for $29.17 \%$ of the core authors; USA and England scholars rank second and third with 15 and 13, respectively. Hong Kong Polytechnic University is the most published scholarly mechanism.

Figure 5 shows the global author cooperation map on green finance. Figure 6 presents the global institutional cooperation map on green finance. The node size represents the number of authors' posts. The thickness of the connection between the nodes indicates the close cooperative relationship.

3.4. Journal Distribution. Periodical analysis of a subject area can determine the distribution of core journals in the subject. Figure 7 shows the journal map of green finance. Table 1 shows the detailed information of the top 10 source publication papers published. Among these publications, 


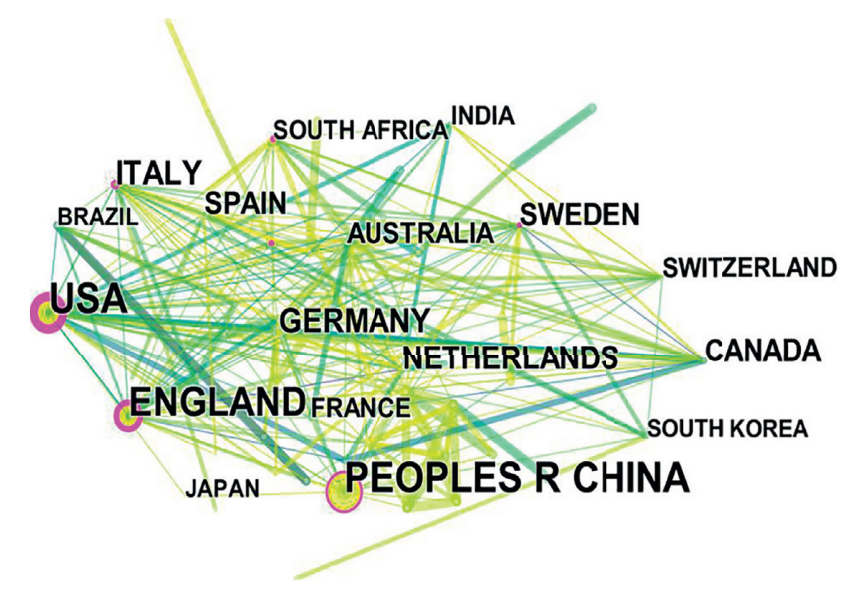

FIGURE 3: Map of national productivity contribution in green finance.

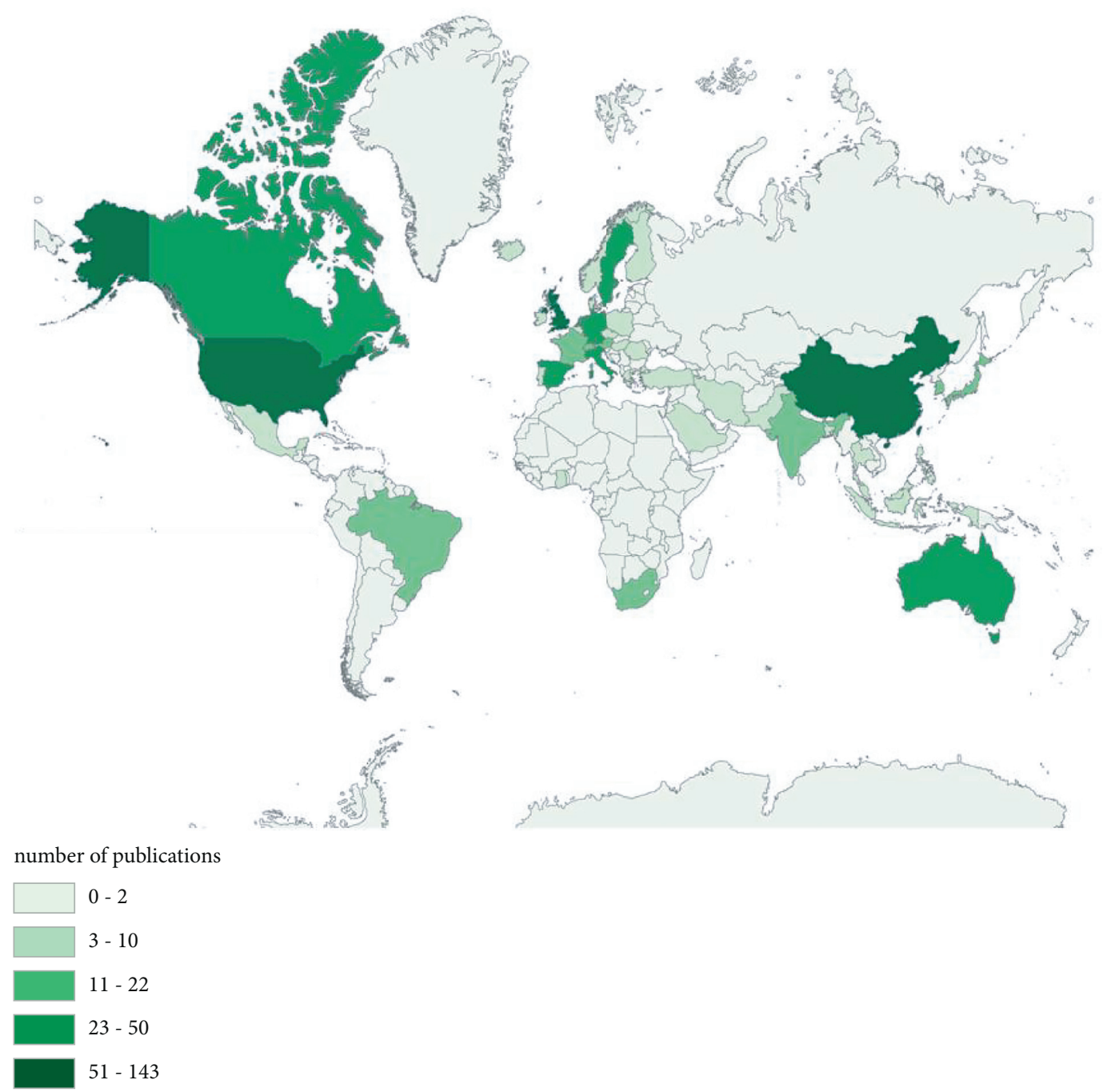

FIGURE 4: Geographical numbers of publications.

the number of top 10 journal publications accounts for $29.39 \%$ of the total, which is a large proportion. The main categories of these core journals are related to energy, resources, sustainable development, economy, management, and geography. It demonstrates that green finance has become the focus of attention of people from all walks of life. Figure 7 is a map of journal productivity contributions. The size of the nodes represents the number 


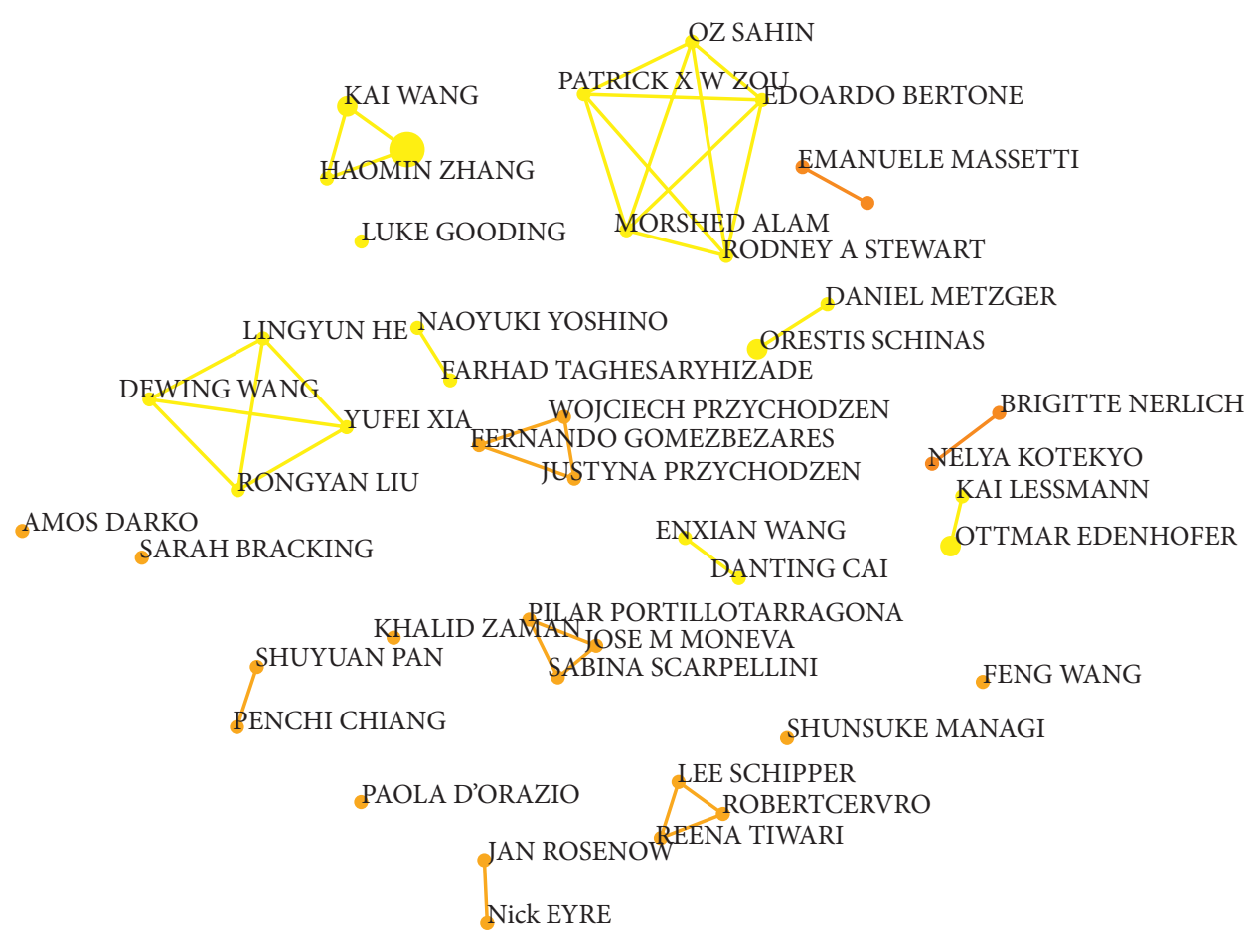

FIGURE 5: Map of author contribution in green finance.

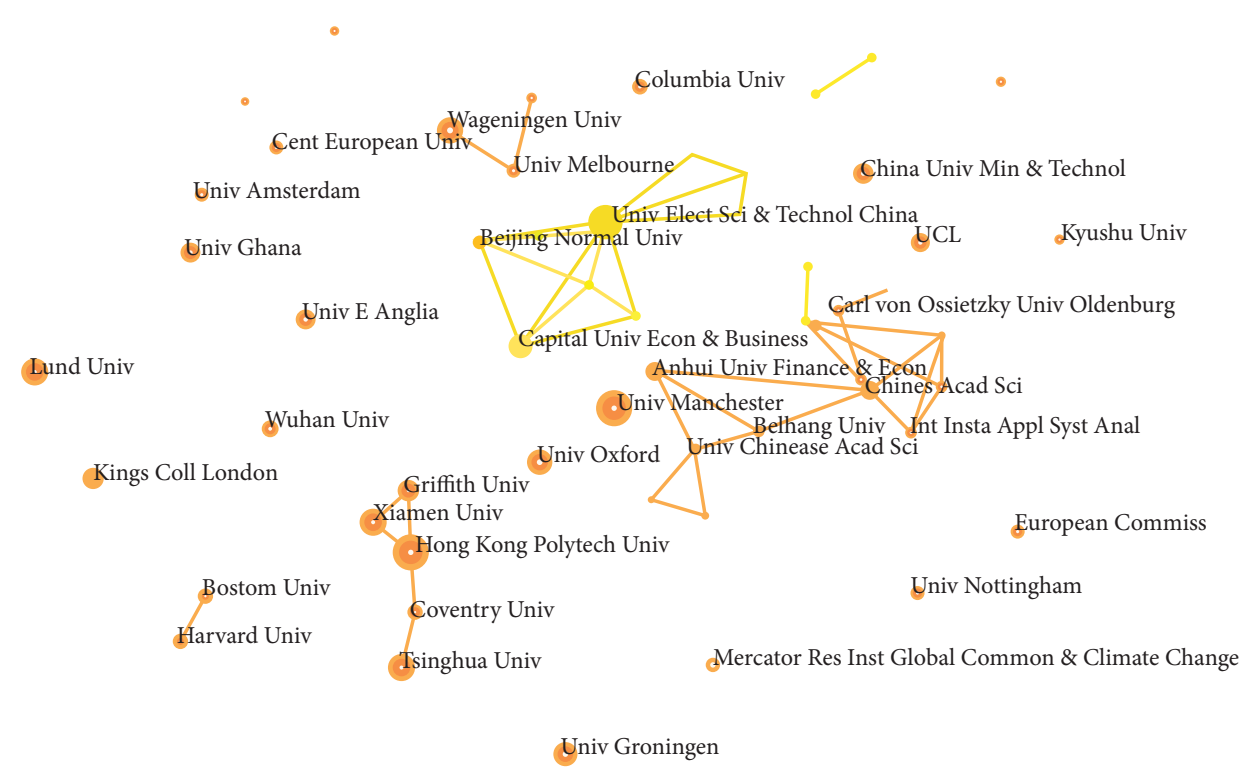

Figure 6: Map of institution contribution in green finance.

of publications, and the line between nodes represents the cocitation relationship between journals. Sustainability is the journal with the highest number of publications on green finance, with a total of 81 papers. However, due to its low degree of centrality, the $H$ index is only 7 , and average number of references per item is 3.76. Although Energy Policy has published 38 articles, the $H$ index is 18 , and average number of references per item is 29.82 , which is a high-quality journal.
3.5. Cocitation Analysis. Citations in the original data form the knowledge base for research in a specific field, while corresponding citations form the research frontier. Figure 8 presents the cluster analysis on cocitation documents using the log-likelihood ratio (LLR) algorithm. The results present distinctive features of large branch number and low overlap level, manifesting that the research on green finance has blossomed and matured. The knowledge group of node papers at the junction plays a role in connecting the group. 


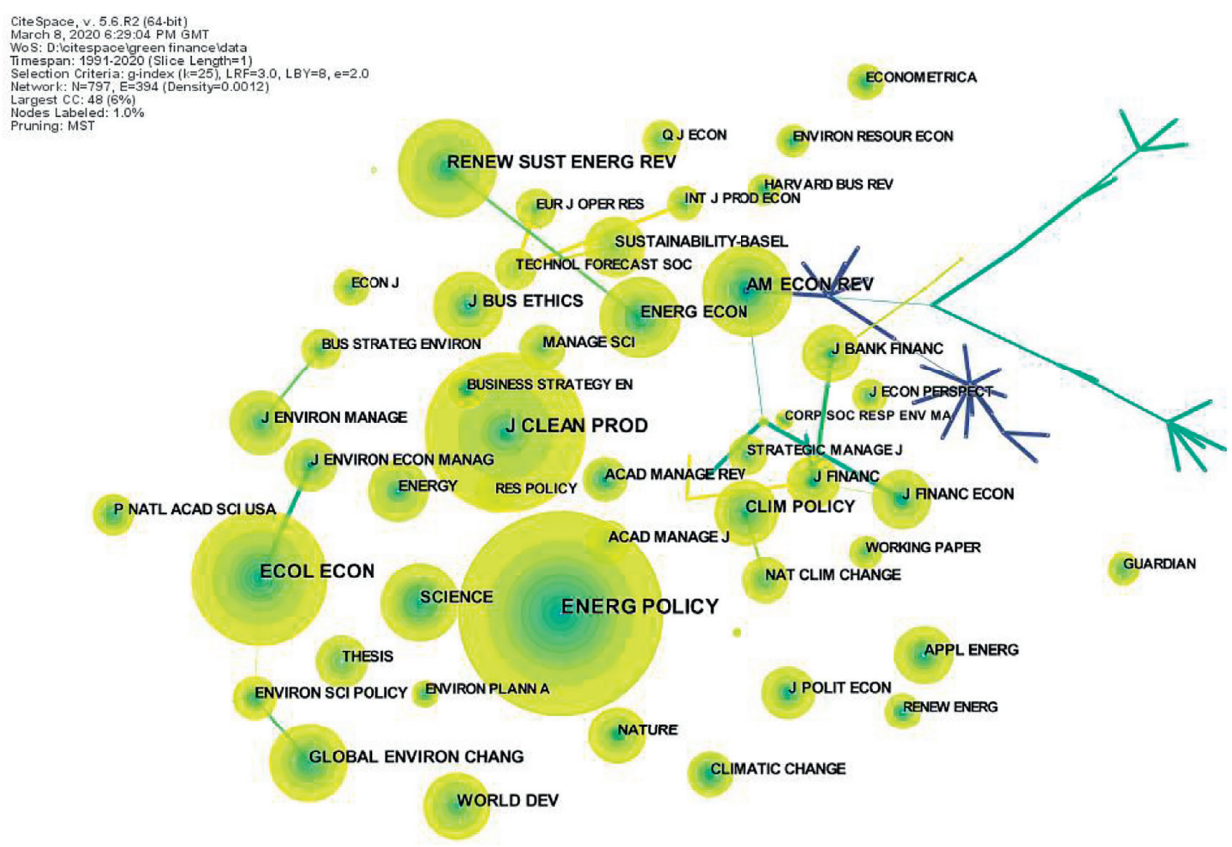

Figure 7: Map of journal contribution in green finance.

TABLE 1: The top 10 productive journals in green finance.

\begin{tabular}{|c|c|c|c|c|}
\hline Journals & NP & NP $R(\%)$ & $H$ index & ANC \\
\hline Sustainability & 81 & 9.121 & 7 & 3.76 \\
\hline Journal of Cleaner Production & 58 & 6.531 & 11 & 17.88 \\
\hline Energy Policy & 38 & 4.279 & 18 & 29.82 \\
\hline Climate Policy & 26 & 0.927 & 7 & 5.90 \\
\hline International Journal of Environmental Research and Public Health & 14 & 1.157 & 3 & 2.71 \\
\hline Business Strategy and the Environment & 13 & 1.469 & 7 & 10.46 \\
\hline Environmental Science and Pollution Research & 13 & 1.469 & 4 & 4.75 \\
\hline Technological Forecasting and Social Change & 9 & 1.013 & 7 & 13.80 \\
\hline Energy Economics & 9 & 1.013 & 5 & 17.67 \\
\hline Land Use Policy & 9 & 1.013 & 8 & 26.44 \\
\hline
\end{tabular}

Notes. NP: number of publications; $R$ (\%): ratio of the number of one journal's publications to the total number of publications; ANC: average number of citations per item.

The number of nodes indicates citation times of the paper and its foundational position. Research methods, technical means, conclusions, and findings of the highly cited literatures promote the development of the whole field, which provide theoretical support and guidance for subsequent research.

According to the clustering structure and sharpness, two indicators, modularity ( $Q$ value) and mean silhouette value ( $S$ value), are used to appraise this map. In the interval $[0,1]$, if the $Q$ value is greater than 0.3 and $S$ value is greater than 0.5 , the clustering result will be regarded reasonable. Figure 8 draws the cocitation literature clustering and exhibits 9 distinct clusters, namely, fostering green investment, business eco-innovation, green entrepreneurship, green bond, green economy, hesitant linguistic term, carbon capture, sustainable practice, and low-carbon economy. However, mean silhouette of the cluster is only 0.24 , and the reference is low, so the silhouette of the subcluster is analyzed. Among the 9 clusters, the top 3 subclusters of $S$ value are business eco-innovation (0.94), fostering green investment (0.79), and green entrepreneurship (0.77). The result shows that the three subclusters are reasonable.

The most active citer to the 1st cluster is defining and measuring different dimensions of financial resources for business eco-innovation and the influence of the firms' capabilities. It uses different dimensions of financial resources for the first time to measure ecological innovation investment and internal management of ecological innovation. The most active citer to the 2 nd cluster is fostering green investments and tackling climate-related financial risks: which role for macroprudential policies? It gives people an idea of how to promote green lending by financial institutions and cope with climate change under macroeconomic policies. The most active citer to the 3 rd cluster is drivers and barriers of eco-innovation types for sustainable transitions: a quantitative perspective. This paper suggests that resource, capacity, and dynamic capacity (RCCs) can be used as determinants of different types of eco-innovation 


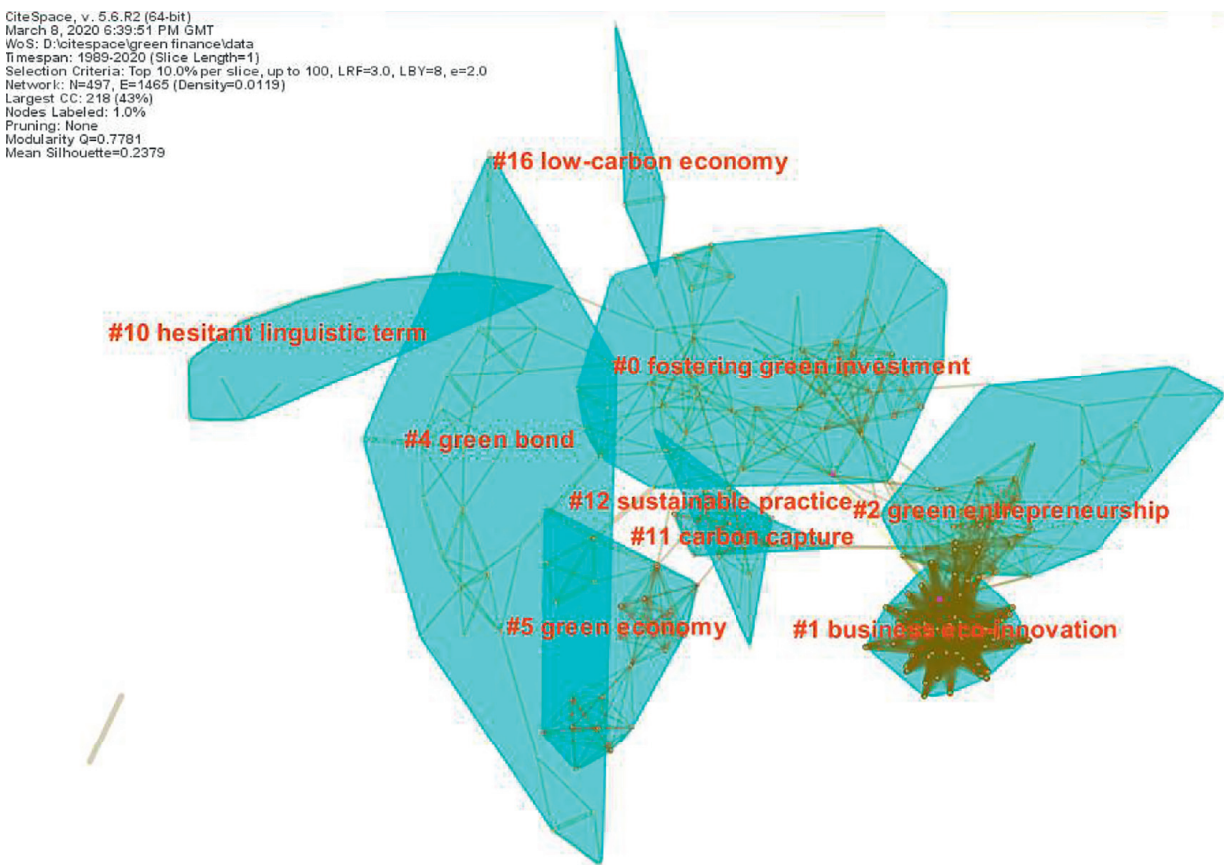

Figure 8: Map of cocited literature clustering in green finance.

(EI) to enhance competition and sustainable advantage for business decision-makers who are willing to promote ecoinnovation.

\section{Research Trend}

To investigate the trend of changes in research topics, the study combines the burst detection of keywords in Figure 9 and the number of document changes in Figure 1 and analyzes the following core themes and hotspots in different periods. The theme evolution of green finance can be divided into three stages, namely, the embryonic stage of research (1991-2011), the stable development stage of research (2012-2017), and the vigorous development stage of research (2018-present).

4.1. The Embryonic Stage of Research (1991-2011). At this stage, scholars around the world have done little research on green finance, and the main keywords were "renewable energy," "health," "environment," and so forth. The research is mainly about the establishment of a basic system of green finance.

As early as the 1980s and early 1990s, civil society organizations launched a campaign against the World Bank, forcing the World Bank to recognize their adverse effects on ecology and nature. This activity is mainly aimed at the four business aspects of the World Bank: environment, technical facilities, poverty, and structural adjustment. An organization different from the World Bank, the International Finance Corporation, established a Ministry of Environment in 1989 with the mission of "promoting sustainable investment in the private sector in developing countries, helping to reduce poverty and improve people's lives." When the environmental department was first established, it selected 7 out of 160 projects that were considered to have significant environmental impacts for investment [14]. After years of development of guidelines, IFC's investment procedures have become the basis for other international financial institutions and export credit agencies [34].

However, IFC is concerned that the company's higher standards have not provided funding for small but environmentally friendly projects. Therefore, the IFC and the 2002 Johannesburg Earth Summit tried to persuade major commercial banks to adopt IFC's environmental and social approach, which further promoted the process of financial sustainability. Many major banks have also signed the UNEP financial initiative. In 2003, 10 major banks announced the adoption of the Equator Principles (EP), which provides a basic framework for environmental risk management in project financing [35]. At this point, the basic system of green finance has basically been established, and major banks have made the "socialization" of finance "green" [36].

Although it is pointed out that the financial industry should move towards a "green" standardization road in the future, how each country should follow the vague and yet untraveled road of development became the top priority of scholars' research in the next stage.

4.2. The Stable Development Stage of Research (2012-2017). This stage is the stable development stage of China's green finance research. The main mutation keywords were country, barrier, competition, and so forth. The concept of green finance at this stage is no longer limited to ecological and environmental protection but has played a role in national and social development which cannot be ignored. The restrictive factors for the development of green finance and how each country should follow the path of green finance have become the subject of this research stage. 
Top 30 Keywords with the Strongest Citation Bursts

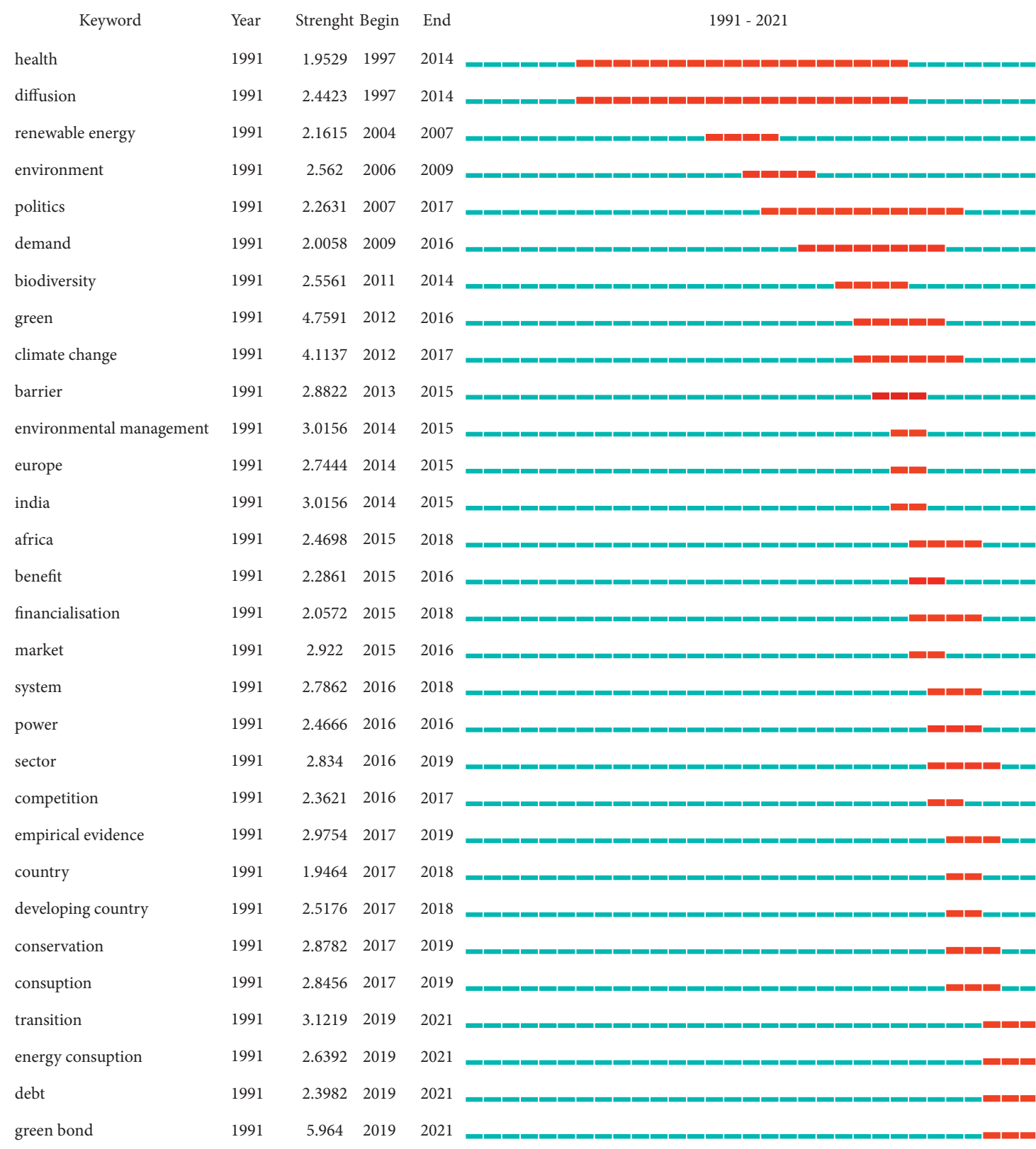

FIGURE 9: Keywords with the strongest citation bursts.

The conclusion that financial activities promote economic growth supports the "finance-led growth" hypothesis. However, the unbridled development of finance has harmed the quality of the environment [37]. Investors only see the immediate profits and will not express their views on the ecological impact of the project in a few years. Therefore, environmentalists and policymakers are keen to formulate "green finance" opportunities in the national policy agenda to improve environmental policies and reform environmental sustainability [12]. The challenging task of financial sustainability is monetized through a fair environmental policy combined with national action plans. Scholars from various countries have also made suggestions and have triggered thinking about sustainable investment [38].
In addition to countries' thinking on financial sustainability, another theme at this stage is about the factors restricting the development of green finance. Researchers are focusing on green finance risks, green finance service systems, green finance standards, green finance information communication, and green finance [37]. There were a series of discussions on products and other aspects: First is the low level of awareness of green finance, which is mainly manifested in the public's lack of clear understanding of green finance, financial institutions still regarding short-term benefits as their goals in practice, and lack of long-term development of green finance, as well as correct understanding and reasonable planning. Second is the lack of green finance theory and technology [39]. Green finance is in 
a relatively marginal state of research, and many theoretical issues have not been resolved, which lack advanced financial product design and financial risk prevention and control, as well as technical support [29]. Third is the imperfect market system, which is mainly manifested in three aspects of financing channels, financing methods, and participants. Financing channels are mainly derived from bank credit in the indirect market, and the direct market is almost blank. Financing methods include working capital loans and project loans; however, other forms such as green securities and some financial derivatives are still rare [40]. In terms of participants, although banks are the main body, they are only a small part of the participants.

In the stable development stage of green finance research, the concept of green finance is no longer limited to ecological and environmental protection construction but has played an important role in national social development. Green finance research integrates environmental friendliness and national strategies well. On this basis, many scholars have discussed the sustainable development of finance and the restrictive factors of green finance in various countries. They believe that green finance is the only way to promote the sustainable development of the financial industry, but there is no definite conclusion on how to develop the green finance system.

4.3. Vigorous Development Stage of Research (from 2018 to Present). At this stage, green finance research has entered a vigorous development stage; the main mutation words are "energy consumption," "green bond," "debt," and so on. During this period, the literature research has changed from the definition of connotation and system design to a more specific issue of green finance development. With the development of green finance influenced deeply by the formulation of national strategies, the cross research of "green Internet of things," "green innovation," "green supply chain," "peak carbon dioxide emissions," "carbon neutrality," and green finance has become the mainstream in this stage.

Compared with the past 15 years, research methods have gradually shifted from content analysis to empirical and textual analysis. Scholars are increasingly inclined to use rigorous data calculations and scientific modeling thinking to analyze the market effect of green finance in depth. For example, Sun [41] used China as an example to study the asymmetric impact of green credit policies and development on the cost and maturity of debt financing for different types of enterprises. Liu [42] found that the debt financing capacity of companies with serious pollution has declined significantly. Oliveira [43] also considered capital constraints and trade controls and analyzed the two contracts of green finance and cost-sharing. The results show that the interest rate of green finance does not have a negative impact on manufacturers' carbon emissions, but cost-sharing may affect manufacturers and has a negative impact on carbon emissions. Subua Barua considered a set of three-dimensional factors, bond grade, issuer characteristics, and market characteristics, and studied their impact on the issuance scale. However, the results only found the impact of bond and issuer ratings on the average financing scale, and market trends did not have a significant impact on the issuance scale.

The significant difference between this stage and the previous periods is that the development of green finance has been greatly sublimated. It is no longer limited to the exploration of connotations and difficulties but actually puts forward beneficial suggestions for social and economic development.

\section{Discussions, Conclusions, and Future Directions}

Over the past three decades, the development issues of green finance have attracted a sharp increase in interest all over the world, especially since 2012. A good many scholars and institutions have made significant contributions to the scientific advances in the green finance field which have been brought to light. Using the bibliometric analysis and visualization techniques on a sample of 888 relevant publications to date, this study provides a systematically structural description of current status and evolution trends on green finance.

The research on green finance has entered an exponential development stage, and the number of publications issued during the development period has increased sharply. As far as the country is concerned, the number of publications from the United States, China, and England is more than 100 , which is much larger than the number of publications from Germany that ranked fourth. The United States and England have higher $H$ indexes. China has a large number of papers, while the $H$ index is only 15 , indicating that although China has a high number of posts, there are relatively fewer high-quality documents. Similarly, in terms of journals, although the number of publications in Sustainability is the first, its $H$ index and average citations per item are far inferior to those of Energy Policy. Chinese scholars account for $29.17 \%$ of the top 120 productive authors, and USA and England scholars rank second and third, respectively. In term of comprehensive strength, USA, England, and China hold the top three spots.

Eight keyword clusters, environment, finance, land grabbing, TOPSIS, innovation diffusion, energy, industrial park, and retrofit, are shown in Figure 10. These clusters could be qualitatively condensed into three dimensions (i.e., purpose, process, and participants, or $3 \mathrm{P}$ ) to facilitate a better understanding and structuring of future research. Through the 3P framework, the relationships among 8 clusters are shown in Figure 11, in which the oval indicates the subject, the three hexagons denote the classification of the 8 clusters under "purpose, process, and participants," and the three rectangles represent the agenda of the $3 \mathrm{P}$ framework.

The "purpose" dimension refers to the motivations for green finance within the global context of sustainable development. The initial motive of green finance is to promote green development. However, after a period of practice, it was found that the funding gap for green development is 


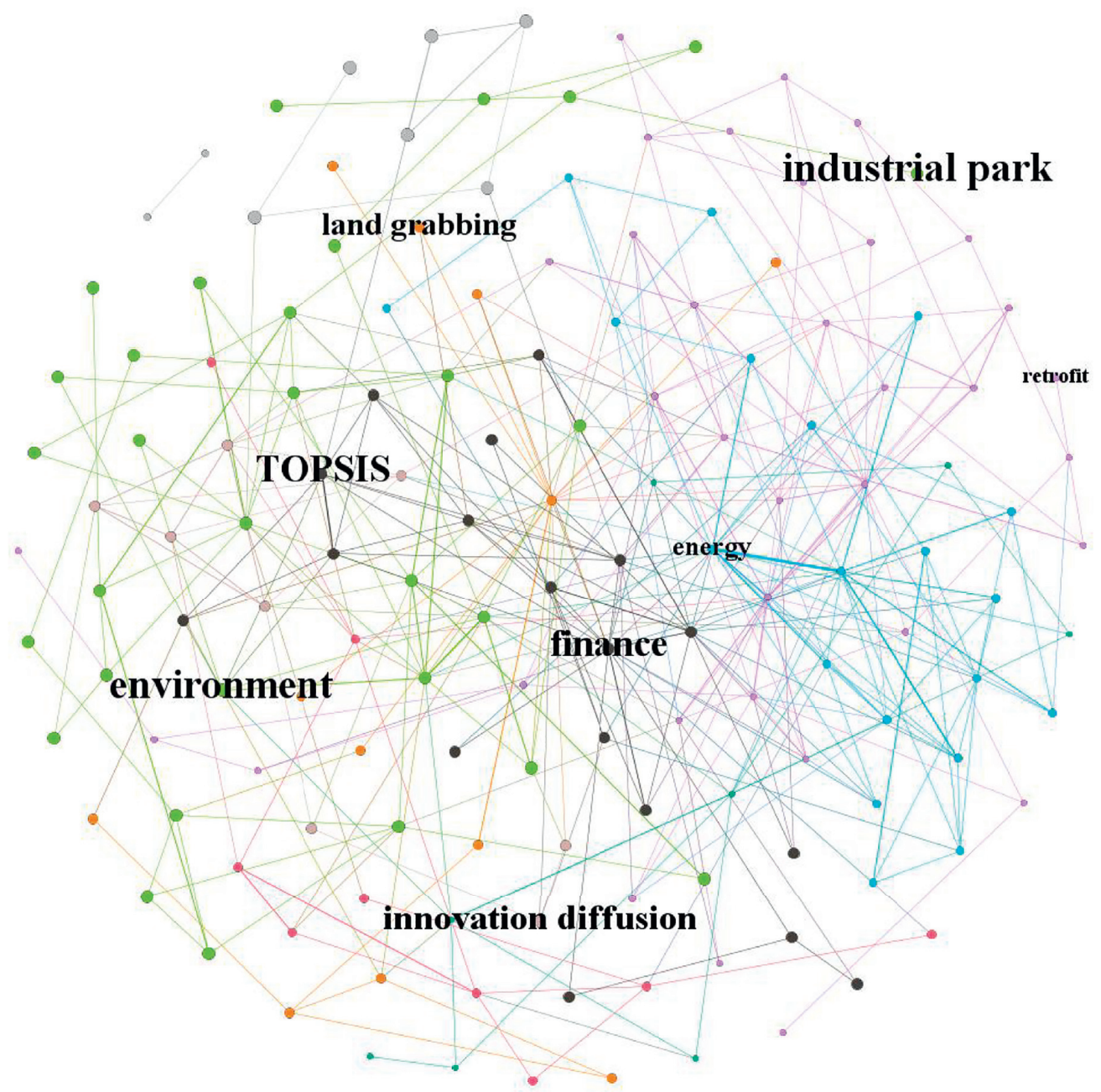

FIgURE 10: Map of keywords clustering in green finance.

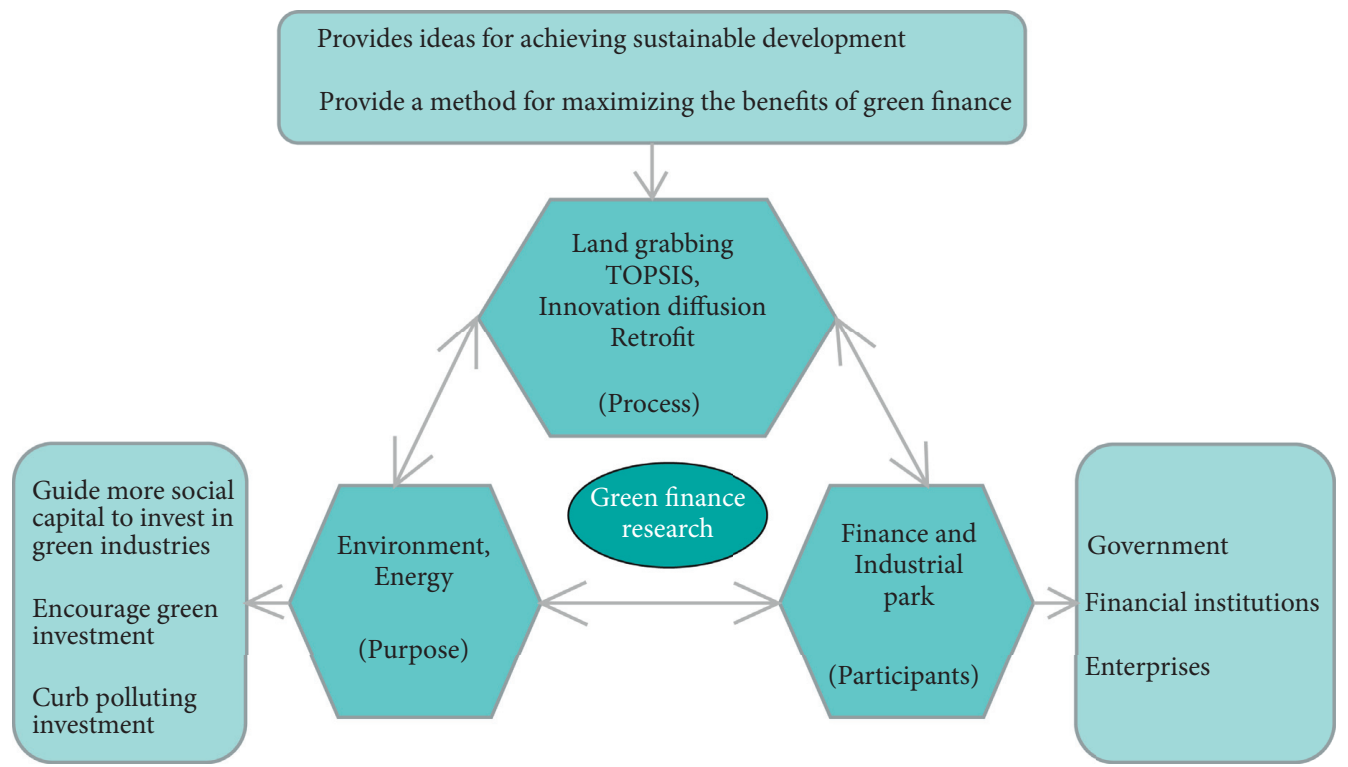

FiguRE 11: 3P framework for green finance research. 
very large, which is not enough to achieve the goal of green finance. Therefore, at present, the purpose of green finance is to guide more social capital to invest in green industries, encourage green investment, and curb polluting investment. While the research of green finance has not formed a system, how to clarify the purpose of each period has become the top priority of future research. Moreover, the proposal for green finance stems from the expectation and pursuit of environmental protection and economic-social conditions. But the question is, what is the best state of green finance? How far have we moved towards the ideal state of green finance? None of these questions have been clearly answered. It is undeniable that the main direction of researches on green finance for a long time was how to make green finance more perfect, but there was a lack of complete grasp and evaluation of the actual situation, which is not conducive to appropriately adjust the current direction. Therefore, future research should increase the level of focus on the green finance evaluation system and designing a holistic plan to evaluate the country's green finance level.

The "process" dimension aims at the actions that affect the society, economy, and environment during project operation. Land grabbing, innovation diffusion, and retrofit provide ideas for achieving sustainable development. TOPSIS provides a method for maximizing the benefits of green finance. However, the current process research is decentralized and independent, and the green financial development mechanism has not been fully established. Next, countries should actively participate in building a common language for global green finance, reduce the transaction costs of green investment, and promote international market interconnection. More attention should be paid to the impact of new policies and technologies on green finance which are rapidly changing the economic and biological forms of society. Although many scholars have begun to pay attention to the interaction between new policies, technologies, and green finance in recent years, the content and novelty are still slightly behind. It can be expected that, with the continuous development and application of new policies and technologies, the impact on green finance is broad and deep.

The "participants" dimension reflects stakeholders in relation to green finance. Market participants such as financial institutions and industries need to combine specific policies with actual business strategies and business processes. However, there are fewer participants on green finance; the research on "participants" is also relatively less and slightly behind. Other financial institutions (e.g., brokerage firms, asset management companies, insurance companies, etc.) and unincorporated participants (e.g., asset managers and wealth managers) should be integratedly included in the market participants. The lack of adequate understanding of green finance by nonbank institutions has led to green financial activities being less carried out. Therefore, great efforts must be devoted to cultivating market participants and improving the financial technology level of market participants in the future.

We have determined the longitudinal theme evolution of the theme through the annual numbers of green finance publications and the burst detection of keywords; however, there are also some subjective factors, and the future of the theme stage needs further evaluation. Secondly, our database only considers SCI-E and SSCI, the database does not include the entire scientific network, and future choices should be more comprehensive [44]. Finally, our framework is based on keyword clustering labels; it may be a better choice to determine the framework based on keywords, although the task is relatively large.

In sum, this study tries to draw the outline of the global review on the latest research and that of newly emerging topics in the field of green finance. The evolution trends, based on the quantity of literature, geographical and periodical distribution, national comprehensive strength, journal distribution, productive authors, and institutions, as well as category, citations, and cocitation analysis, might help researchers to identify their positions in a global context, grasp research hotspots, understand valuable ideas, and develop more specific targets for their work.

\section{Data Availability}

The sources of data input in our research are the Science Citation Index Expanded (SCI-E, 1900-2020) and Social Sciences Citation Index (SSCI, 1983-2020) from the Web of Science.

\section{Conflicts of Interest}

The authors declare that they have no conflicts of interest.

\section{Acknowledgments}

This study was funded by the National Natural Science Foundation of China (Grant no. 717711257), Major Project of Natural Science Foundation of Jiangsu Education Department (19KJA180002), and Open Project of Jiangsu Key Laboratory of Public Project Audit (Grant no. GGSS2016$03)$.

\section{References}

[1] M. Han, H. Lin, J. Wang, Y. Wang, and W. Jiang, "Turning corporate environmental ethics into firm performance: the role of green marketing programs," Business Strategy and the Environment, vol. 28, no. 6, pp. 929-938, 2019.

[2] H. Lin, S. X. Zeng, H. Y. Ma, G. Y. Qi, and V. W. Y. Tam, "Turning corporate environmental ethics into firm performance: the role of green marketing programs," Journal of Cleaner Production, vol. 64, pp. 63-72, 2014.

[3] P. Sukhdev, "The corporate climate overhaul," Nature, vol. 486, no. 7401, pp. 27-28, 2012.

[4] D. Sun, S. Zeng, H. Lin, X. Meng, and B. Yu, "Can transportation infrastructure pave a green way? A city-level examination in China," Journal of Cleaner Production, vol. 226, pp. 669-678, 2019.

[5] H. Lin, S. X. Zeng, H. Y. Ma, and H. Q. Chen, "How political connections affect corporate environmental performance: the mediating role of green subsidies," Human and Ecological Risk Assessment: An International Journal, vol. 21, no. 8, pp. 2192-2212, 2015. 
[6] A. A. Nassani, A. M. Aldakhil, M. M. Qazi Abro, and K. Zaman, "Environmental Kuznets curve among BRICS countries: spot lightening finance, transport, energy and growth factors," Journal of Cleaner Production, vol. 154, pp. 474-487, 2017.

[7] R. D. Marchand, S. C. L. Koh, and J. C. Morris, "Delivering energy efficiency and carbon reduction schemes in England: lessons from green deal pioneer places," Energy Policy, vol. 84, pp. 96-106, 2015.

[8] S. Hafner, A. Jones, A. Anger-Kraavi, and J. Pohl, "Closing the green finance gap - a systems perspective," Environmental Innovation and Societal Transitions, vol. 34, pp. 26-60, 2020.

[9] A. W. Ng, "From sustainability accounting to a green financing system: institutional legitimacy and market heterogeneity in a global financial centre," Journal of Cleaner Production, vol. 195, pp. 585-592, 2018.

[10] C. P. Naidoo, "Relating financial systems to sustainability transitions: challenges, demands and design features," Environmental Innovation and Societal Transitions, vol. 36, pp. 270-290. In press, 2020.

[11] D. Zhang, Z. Zhang, and S. Managi, "A bibliometric analysis on green finance: current status, development, and future directions," Finance Research Letters, vol. 29, pp. 425-430, 2019.

[12] F. W. Geels, "The impact of the financial-economic crisis on sustainability transitions: financial investment, governance and public discourse," Environmental Innovation and Societal Transitions, vol. 6, pp. 67-95, 2013.

[13] A. Ward, P. Dargusch, S. Thomas, Y. Liu, and E. A. Fulton, “A global estimate of carbon stored in the world's mountain grasslands and shrublands, and the implications for climate policy," Global Environmental Change, vol. 28, pp. 14-24, 2014.

[14] IFC, Green Finance: A Bottom-Up Approach to Track Existing Flows, International Finance Corporation, Washington, DC, USA, 2017.

[15] P. Demirel and G. O. Danisman, "Eco-innovation and firm growth in the circular economy: evidence from European small- and medium-sized enterprises," Business Strategy and the Environment, vol. 28, no. 8, pp. 1608-1618, 2019.

[16] P. T. I. Lam and A. O. K. Law, "Crowdfunding for renewable and sustainable energy projects: an exploratory case study approach," Renewable and Sustainable Energy Reviews, vol. 60, pp. 11-20, 2016.

[17] J. P. Nugent, "Ontario's infrastructure boom: a socioecological fix for air pollution, congestion, jobs, and profits," Environment \& Planning A, vol. 47, no. 12, pp. 2465-2484, 2015.

[18] S. Scarpellini, L. M. Marín-Vinuesa, P. Portillo-Tarragona, and J. M. Moneva, "Defining and measuring different dimensions of financial resources for business eco-innovation and the influence of the firms' capabilities," Journal of Cleaner Production, vol. 204, pp. 258-269, 2018.

[19] D.-J. Van de Ven, J. Sampedro, F. X. Johnson et al., "Integrated policy assessment and optimisation over multiple sustainable development goals in eastern Africa," Environmental Research Letters, vol. 14, no. 9, Article ID 094001, 2019.

[20] J. W. Bolderdijk, L. Steg, E. S. Geller, P. K. Lehman, and T. Postmes, "Comparing the effectiveness of monetary versus moral motives in environmental campaigning," Nature Climate Change, vol. 3, no. 4, pp. 413-416, 2013.

[21] P. Guertler, "Can the Green Deal be fair too? Exploring new possibilities for alleviating fuel poverty," Energy Policy, vol. 49, pp. 91-97, 2012.
[22] C. Ghisetti, S. Mancinelli, M. Mazzanti, and M. Zoli, "Financial barriers and environmental innovations: evidence from EU manufacturing firms," Climate Policy, pp. S131S147, 2017.

[23] D. L. Greene, "What is greener than a VMT tax? The case for an indexed energy user fee to finance us surface transportation," Transportation Research Part D: Transport and Environment, vol. 16, no. 6, pp. 451-458, 2011.

[24] A. P. C. Chan, A. Darko, A. O. Olanipekun, and E. E. Ameyaw, "Critical barriers to green building technologies adoption in developing countries: the case of Ghana," Journal of Cleaner Production, vol. 172, pp. 1067-1079, 2018.

[25] R. Clark, J. Reed, and T. Sunderland, "Bridging funding gaps for climate and sustainable development: pitfalls, progress and potential of private finance," Land Use Policy, vol. 71, pp. 335-346, 2018.

[26] S.-Y. Pan, M. A. Du, I.-T. Huang, I.-H. Liu, E.-E. Chang, and P.-C. Chiang, "Strategies on implementation of waste-toenergy (WTE) supply chain for circular economy system: a review," Journal of Cleaner Production, vol. 108, pp. 409-421, 2015.

[27] R. Fletcher, W. H. Dressler, Z. R. Anderson, and B. Büscher, "Natural capital must be defended: green growth as neoliberal biopolitics," Journal of Peasant Studies, vol. 46, no. 5, pp. 1068-1095, 2019.

[28] H. Winkler and N. K. Dubash, "Who determines transformational change in development and climate finance?" Climate Policy, vol. 16, no. 6, pp. 783-791, 2016.

[29] G. Wang, P. Wu, X. Wu, H. Zhang, Q. Guo, and Y. Cai, "Mapping global research on sustainability of megaproject management: a scientometric review," Journal of Cleaner Production, vol. 259, Article ID 120831, 2020.

[30] J. Yin, L. Gong, and S. Wang, "Large-scale assessment of global green innovation research trends from 1981 to 2016: a bibliometric study," Journal of Cleaner Production, vol. 197, pp. 827-841, 2018.

[31] C. Chen, "Searching for intellectual turning points: progressive knowledge domain visualization," Proceedings of the National Academy of Sciences, vol. 101, no. S1, pp. 5303-5310, 2004.

[32] M. R. W. Rands, W. M. Adams, L. Bennun et al., "Biodiversity conservation: challenges beyond 2010," Science, vol. 329, no. 5997, pp. 1298-1303, 2010.

[33] D. J. S. Price, "Little science, big science- and beyond," von der studierstube zur, vol. 7, no. 3-6, pp. 443-458, 1963.

[34] V. Czakó, "Evolution of Hungarian residential energy efficiency support programmes: road to and operation under the Green Investment Scheme," Energy Efficiency, vol. 5, no. 2, pp. 163-178, 2012.

[35] B. Scholtens and L. Dam, "Banking on the Equator. Are banks that adopted the Equator Principles different from nonadopters?" World Development, vol. 35, no. 8, pp. 1307-1328, 2007.

[36] S. Wunder, S. EngeL, and S. Pagiola, "Taking stock: a comparative analysis of payments for environmental services programs in developed and developing countries," Ecological Economics, vol. 65, no. 4, pp. 834-852, 2008.

[37] C. Criscuolo and C. Menon, "Environmental policies and risk finance in the green sector: cross-country evidence," Energy Policy, vol. 83, pp. 38-56, 2015.

[38] M. Singal, "The link between firm financial performance and investment in sustainability initiatives," Cornell Hospitality Quarterly, vol. 55, no. 1, pp. 19-30, 2014. 
[39] T. D. Corsatea, S. Giaccaria, and R. L. Arántegui, "The role of sources of finance on the development of wind technology," Renewable Energy, vol. 66, pp. 140-149, 2014.

[40] S. Copiello, "Leveraging energy efficiency to finance public-private social housing projects," Energy Policy, vol. 96, pp. 217-230, 2016.

[41] J. Sun, F. Wang, H. Yin, and B. Zhang, "Money talks: the environmental impact of China's green credit policy," Journal of Policy Analysis and Management, vol. 38, no. 3, pp. 653-680, 2019.

[42] X. Liu, E. Wang, and D. Cai, "Green credit policy, property rights and debt financing: quasi-natural experimental evidence from China," Finance Research Letters, vol. 29, pp. 129-135, 2019.

[43] G. A. Oliveira, K. H. Tan, and B. T. Guedes, "Lean and green approach: an evaluation tool for new product development focused on small and medium enterprises," International Journal of Production Economics, vol. 205, pp. 62-73, 2018.

[44] H. Barton, "Land use planning and health and well-being," Land Use Policy, vol. 26, pp. S115-S123, 2009. 